\title{
Substâncias húmicas e relação com atributos edáficos
}

\author{
Adierson Gilvani Ebeling ( $\left.{ }^{(}\right)$; Lúcia Helena Cunha dos Anjos (2*); Marcos Gervasio Pereira ( $\left.{ }^{2}\right)$; \\ Érika Flavia Machado Pinheiro $\left({ }^{2}\right)$; Gustavo Souza Valladares ( $\left.{ }^{3}\right)$ \\ (') Doutorando em Agronomia Ciência do Solo - CPGA-CS, Universidade Federal Rural do Rio de Janeiro (UFRRJ). Bolsista do CNPq. \\ E-mail: adiersonge@gmail.com \\ (2) Departamento de Solos, UFRRJ. BR 465 km 7, 23890-000 Seropédica (RJ). E-mail lanjos@ufrrj.br (*) Autora correspondente; \\ gervasio@ufrrj.br; Bolsistas de Produtividade do CNPq; Erika@ufrrj.br \\ (3) Centro de Ciências Agrárias, Departamento de Ciências do Solo, Universidade Federal do Ceará (UFC). Av. Mister Hull, 2977, \\ Campus do Pici, Caixa postal 12168,60021-970 Fortaleza (CE).E-mail valladares@ufc.br
}

Recebido: 13/fev./2009; Aceito: 22/jun./2010

\section{Resumo}

Este trabalho teve como objetivo caracterizar a distribuição das substâncias húmicas (ácidos fúlvicos livres, ácidos húmicos, ácidos fúlvicos e humina) e atributos edáficos em perfis de solos de diferentes regiões do Brasil, que foram objeto de estudos de reuniões de correlação e levantamentos de solos realizados pela Embrapa e outras instituições. As amostras foram selecionadas e fracionadas seguindo conceitos da IHSS. A fração humina apresentou os maiores valores de C em todos os perfis, seguida pelos ácidos fúlvicos livres. Nos perfis em ambientes com altitudes elevadas o clima (Cwa, Cfb, Cwb) favoreceu a formação dos ácidos fúlvicos livres. Quanto às propriedades químicas, em ambos os horizontes foram verificados coeficientes de correlação positiva entre o hidrogênio e o conteúdo de carbono orgânico, $r=0,58^{*}$ e $r=0,83^{* *}$, para os horizontes A e B, respectivamente. Dentre as substâncias húmicas a de melhor correlação com o conteúdo de carbono orgânico foi a fração humina, com $r=0,89^{* *}$ e $r=0,91^{* *}$ para os horizontes $A$ e B, respectivamente. Foi observada correlação positiva $(p<0,05)$ entre a areia grossa e os C-FAF, C-FAH, C-HUM e a relação C-EA:C-HUM, nos horizontes A, indicando que a textura mais arenosa de alguns horizontes superficiais favorece a formação destas substâncias húmicas. $\mathrm{O}$ teor de $\mathrm{C}$ nos horizontes superficiais e subsuperficiais e a distribuição das substâncias húmicas variaram com a pedogênese e a altitude.

Palavras-chave: Matéria orgânica do solo, granulometria, classificação de solos.

\section{Humic substances and relationship to soil attributes}

\section{Abstract}

This study had as objective to characterize the distribution of humic substances (free fulvic acids, humic acids, fulvic acids, and humin) in soil profiles from different regions of Brazil, that had been object of studies of correlation meetings and soils surveys carried through by Embrapa and other institutions. The soil samples were selected and fractionated following concepts recognized by the IHSSS. The humin fraction presented the highest values of $\mathrm{C}$ in all the profiles, followed by the free fulvic acid fraction. In the profiles located on high altitude the climate (Cwa, Cfb, Cwb) favored the formation of free fulvic acid. As for the chemical properties, both horizons showed positive correlation coefficients between hydrogen and organic carbon content, with $r=0.58^{*}$ and $r=0.83^{* *}$ for $A$ and $B$ horizons, respectively. Amongst the humic substances the humin showed the best correlation with the organic carbon content, with $r=0.89^{* *}$ and $r=0.91^{* *}$ ) for $A$ and $B$ horizons, respectively. A positive correlation was observed between the coarse sand fraction and the C-FAF, C-HAF, C-HUM and the relation C-EA:CHUM in the A horizons, indicating that the coarse texture of some surface horizons favors the formation of these humic substances. The organic C content in the surface and subsurface horizons and the distribution of humic substances varied with pedogenesis and altitude conditions.

Key words: Soil organic matter, granulometry, soil classification. 


\section{INTRODUÇÃO}

Os Latossolos, Argissolos e Cambissolos constituem classes de solos dominantes no território brasileiro, em grande parte das áreas agricultáveis. Em ambiente tropical e, especialmente, em solos fortemente intemperizados, a matéria orgânica do solo (MOS) desempenha papel muito importante nas propriedades químicas e físicas do solo (Anjos et al., 2008). Por outro lado, a substituiçáo da vegetação nativa para implantação de sistemas agrícolas ou de pecuária conduz à alteração na qualidade e no conteúdo de carbono orgânico (Corg) na camada superficial dos solos, sendo esta uma das principais fontes de emissão de $\mathrm{CO}_{2}, \mathrm{CH}_{4}$ e outros gases de efeito estufa para a atmosfera, atribuída ao manejo agrícola das terras (RosCOE, 2003; Johnson et al., 2007).

A taxa de acumulação de Corg no solo depende da sua textura e estrutura, da precipitação pluvial e temperatura, e do sistema de preparo e manejo do solo. Segundo LAL (2004a,b), a conversão de ecossistemas naturais para a agricultura causa a redução do estoque de Corg no solo em cerca de $60 \%$ em ambientes temperados e de $75 \%$ ou mais em solos cultivados nos trópicos. $\mathrm{O}$ mesmo autor cita taxas de sequestro de $\mathrm{C}$ variando de 0 a $150 \mathrm{~kg} \mathrm{C}$ ha $^{-1}$ nno $^{-1} \mathrm{em}$ regióes quentes e secas e de 100 a $1000 \mathrm{~kg} \mathrm{C}$ $\mathrm{ha}^{-1} \mathrm{ano}^{-1} \mathrm{em}$ regiōes úmidas e frias.

Em geral, a caracterização dos solos para fins taxonômicos e de fertilidade é feita através do teor total de Corg. Entretanto, pedoambientes distintos possuem diferenças significativas na constituição da MOS e na distribuição das substâncias húmicas (SHs) (Benites et al., 1998; 2001). Além disso, as características químicas e estruturais da MOS e sua interação com a fração mineral vão determinar sua intensidade de transformação no solo (BENITES et al., 2003).

Uma das formas de avaliação da qualidade da MOS tem sido a quantificação do teor de carbono relacionado às SHs. Essas substâncias constituem de $70 \%$ a $80 \%$ da MOS e através de seus grupos carboxílicos, fenólicos e aminos, influenciam nas propriedades químicas, físicas e biológicas de águas, solos e sedimentos (CunHA et al., 2000). A caracterização das SHs e suas proporções na MOS são, portanto, essenciais para se entender a sustentação dos diferentes sistemas agrícolas, o ciclo global do carbono, a lixiviação de espécies químicas causando poluição das águas e empobrecimento do solo (BAYER et al., 2002).

Trabalhos desenvolvidos recentemente no Brasil vêm tentando estabelecer propriedades relacionadas a substâncias húmicas que poderiam ser utilizadas na separação de horizontes (atributo diagnóstico), ou mesmo no estabelecimento de relaçóes como as propriedades que conotam fertilidade do solo.

Esses trabalhos estão relacionados aos desenvolvidos por Fontana et al. (2008), nos quais relatam que a distribuição das substâncias húmicas pode ser usada como parâmetro para o entendimento dos processos pedogenéticos e para a caracterização de ordens e horizontes diagnósticos do SiBCS. Em outro trabalho, VAlLadares et al. (2003) destacaram a utilização das substâncias húmicas para a ordem dos Organossolos como atributo diagnóstico, ou seja, uma característica diferencial para os níveis de família e série ( $5 .^{\circ}$ e $6 .^{\circ}$ nível categórico), que foi apresentada na 2. ${ }^{a}$ edição do SiBCS (EMBrapa, 2006). A utilização do índice C-FAH/C-FAF e C-EA/C-HUM pode ser útil como parâmetros para a caracterizaçáo das classes de solos no Sistema Brasileiro de Classificação de Solos. (Fontana et al., 2008).

A caracterização das $\mathrm{SH}$ e de sua relação com os atributos do solo é relevante para propor sistemas agrícolas sustentáveis, bem como compreender processos pedogenéticos. Este trabalho teve como objetivo caracterizar a distribuição das substâncias húmicas (ácidos fúlvicos livres, ácidos húmicos, ácidos fúlvicos e humina) e atributos edáficos em horizontes diagnósticos de perfis de solos provenientes de várias regióes do Brasil.

\section{MATERIAL E MÉTODOS}

Para este trabalho foram utilizadas amostras de horizontes diagnósticos superficiais e subsuperficiais de perfis de solo de diferentes regiōes do Brasil, que foram objeto de estudos de Reunióes de Correlaçáo e Classificação de Solos no país. Os perfis foram selecionados a partir da soloteca da Embrapa Solos, por terem materiais de origem, rochas e/ ou sedimentos, de natureza variada, além de coberturas vegetais distintas (Tabela 1). Foram escolhidos 18 perfis nos seguintes Estados: Santa Catarina, Paraná, São Paulo, Minas Gerais, Mato Grosso, Mato Grosso de Sul, Acre e Pará.

O fracionamento das $\mathrm{SH}$ foi feito em triplicata, nas 36 amostras dos horizontes diagnósticos, de acordo com a metodologia proposta por Kononova (1966). Foram determinados os teores de carbono das frações ácidos fúlvicos livres (C-FAFL), ácidos húmicos (C-FAH), ácidos fúlvicos (C-FAF), humina (C-HUM) e o carbono orgânico total (COT) (EMBrAPA, 1997). As concentraçóes de dicromato de potássio utilizadas foram calculadas de forma que $10 \%$ a $75 \%$ do oxidante fossem consumidos na reação, mantendo a titulação dentro da faixa linear de correlaçáo com o teor de carbono (Nelson e Sommers, 1982). Foram calculadas as relaçôes entre as fraçôes húmicas, carbono ácido húmico e carbono ácido fúlvico (C-FAH/C-FAF), relação entre o carbono do extrato alcalino (C-EA=carbono ácido fúlvico + carbono ácido húmico) com o carbono da fração humina (C-EA/C-HUM).

Os baixos valores dessa relaçáo (C-EA/C-HUM (s $0,50)$ são indicativos da forte estabilidade e/ou interação da matéria orgânica com a matriz mineral, podendo 
assim, ser analisado como indicador da estabilidade da matéria orgânica do solo. Esse valor indica o predomínio da humina, sendo observado em horizontes A chernozêmico, principalmente, e outros horizontes minerais. Nos horizontes A chernozêmico, os baixos valores dessa relação são condicionados pela relação entre a matéria orgânica e os íons cálcio e/ou magnésio com a matriz mineral do solo (Kononova, 1966). Para os demais horizontes minerais, os baixos valores estáo relacionados aos teores de argila (ZeCH et al., 1997).

Os altos valores dessa relação (C-EA/C-HUM $(\geq 2,0)$ são indicativos da movimentação das fraçôes alcalinosolúveis dentro do perfil de solo e de zonas de acúmulo de carbono orgânico, podendo assim ser analisado como indicador da capacidade iluvial dos solos (Benites et al., 2001 e 2003b). Esse valor indica o predomínio das fraçôes alcalino-solúveis (ácidos fúlvicos e húmicos) e é observado em horizontes subsuperficiais B espódico e B ou $\mathrm{C}$ glei. Esse comportamento deve-se à natureza solúvel da matéria orgânica (ácidos fúlvicos e ácidos húmicos) que percola no perfil, enquanto a humina, por sua natureza pouco solúvel, concentra-se nas camadas superficiais (Benites et al., 2001). Nesse grupo, deve-se excluir os horizontes $\mathrm{A}$ enterrado e $\mathrm{C}$ com caráter flúvico, pois ambos não possuem evidências de iluviação de matéria orgânica e sim outros processos, além do que, tendem a ter valores dessa relaçáo $<1,0$, o que indica o predomínio da humina.

Os teores de carbono nas fraçóes húmicas e seu percentual em relação ao carbono total (COT) foram comparados entre si e entre estes e as demais formas de carbono, utilizando o método de correlação de Pearson. Ainda, procurou-se identificar a relação entre os teores de $\mathrm{C}$ nas fraçôes húmicas e destas com alguns atributos edáficos.

\section{RESULTADOS E DISCUSSÃO}

\section{Relação entre as frações húmicas e o carbo- no total}

A maior parte do $\mathrm{C}$ total presente nos solos (Tabela 2) foi composta pelo carbono da fraçáo humina (C-HUM) (Figura 1), com valor mínimo de $1,0 \mathrm{~g} \mathrm{~kg}^{-1}$ média de 14,0 $\mathrm{g} \mathrm{kg}^{-1}$ e máximo de $49,0 \mathrm{~g} \mathrm{~kg}^{-1}$. O C-HUM, no conjunto dos horizontes avaliados, proporcionou a melhor correlação com o C orgânico total $\left(\mathrm{r}^{2}=0,92, \mathrm{p}=0,01\right)$ e a menor variação em termos relativos, representando em média 59\% do C orgânico total.

A humina é a fração do $C$ que está mais intimamente associada aos colóides minerais do solo, estando aleatoriamente distribuída nos perfis (CANellas et al., 2000). A predominância da fração humina deve-se às suas características de alta massa molecular e à forte interação com a fração mineral do solo conferindo resistência à degradação microbiana (OrLov, 1992; STEVENson, 1994). Ainda em termos de seqüestro de carbono, a humina deve ser considerada a fração mais significativa como reserva de carbono orgânico no solo (FERreira et al., 2004).

Fontana et al. (2001) estudando o comportamento da MOS em Latossolos Amarelos (LA), Argissolos Amarelos e Cambissolos, em Campos dos Goytacazes, sob diferentes coberturas vegetais, também observaram maiores valores para o C-HUM sob LA, indicando

Tabela 1. Legenda de classe de solo, material de origem e localização dos perfis

\begin{tabular}{lccc} 
Perfil & Legenda de Classe de Solo & Material de origem & Localização \\
P1 & LAw & Charnokitos, migmatitos e gnaisses & Juiz de Fora, MG \\
P2 & LAd & Migmatitos & Campina Grande do Sul, PR \\
P3 & LVd & Migmatitos & Pouso Alegre, MG \\
P4 & LAd & Gnaisses e migmatitos & Juiz de Fora, MG \\
P5 & CXbd & Gnaisses & São José dos Pinhais, PR \\
P6 & PAd & Rochas alcalinas & Caldas, MG \\
P7 & LBd & Basalto & Pitanga, PR \\
P8 & LBd & Basalto & Guarapuava, PR \\
P9 & LVef & Basalto & Londrina, PR \\
\hline P10 & MTo & Basalto & EMPAER, PR \\
P11 & PAd & Rochas eruptivas básicas & Água Doce, SC \\
\hline P12 & LBd & Saprólito rochas básicas & Campos Novos, SC \\
P13 & LVd & Argilitos & Artur Nogueira, SP \\
P14 & LVd & Arenitos com cimento argiloso & Assis, SP \\
\hline P15 & PVd & Cobertura argilo-laterítica & Porto Esperidião, MT \\
\hline P16 & PVd & Sedimentos argilo-arenosos & Brasiléia, AC \\
\hline P17 & PAd & Sedimentos Barreiras & Capanema, PA \\
\hline P18 & MTo & Calcáreo & Corumbá, MS \\
\hline
\end{tabular}

LAw - Latossolo Amarelo Ácrico típico; LAd - Latossolo Amarelo Distrófico típico; LVd - Latossolo Vermelho Distrófico típico; CXbd - Cambissolo Háplico Tb Distrófico latossólico; PAd - Argissolo Amarelo Distrófico latossólico; LBd - Latossolo Bruno Distrófico típico; LVef - Latossolo Vermelho Eutroférrico típico; MTo - Chernossolo Argilúvico Órtico típico; PVd - Argissolo Vermelho Distrófico latossólico; PVd - Latossolo Vermelho Distrófico arenossólico. (EMBrapa/CNPS, 2006) 
maior resistência dessa fração à decomposição devido à ligação mais estável com a fração mineral do solo. Dessa forma, a ordem dos Latossolos pode estar propiciando maior grau de humificação da $\mathrm{MO}$ no C-HUM, quando comparado com a ordem dos Argissolos e Cambissolos. Este comportamento demonstra o efeito da textura na manutenção da MOS.

O índice utilizado para a avaliação do grau de humificaçáo da MOS, a relaçáo C-FAH/C-FAF, revelou redução da relação C-FAH/C-FAF do horizonte A para o $\mathrm{B}$, em vários perfis (Tabela 2). Para solos mais argilosos (perfis: 2, 6, 11 e 13) este decréscimo da relação C-FAH/C-FAF foi menos evidente quando comparado com os solos mais arenosos (perfis 3, 5, 10, 15, 16, 17 e 18). Para os perfis $1,4,7,8,9,12$ e 14 essa relaçáo aumentou do horizonte A para o horizonte B, devido à rápida mineralização dos restos vegetais e à formação de materiais pré-húmicos solúveis. Estas substâncias húmicas mais móveis podem migrar para o horizonte $\mathrm{B}$, sua acumulação pode explicar o aparecimento de características estruturais particulares, como uma consistência mais forte, ligada à desorganização estrutural do horizonte B (Volkoff et al, 1978). Estes mesmos perfis também proporcionaram maior quantidade de C-FAF em relaçáo ao $\mathrm{C}-\mathrm{FAH}$ para o horizonte $\mathrm{A}$, o que não foi visto para o horizonte $\mathrm{B}$.
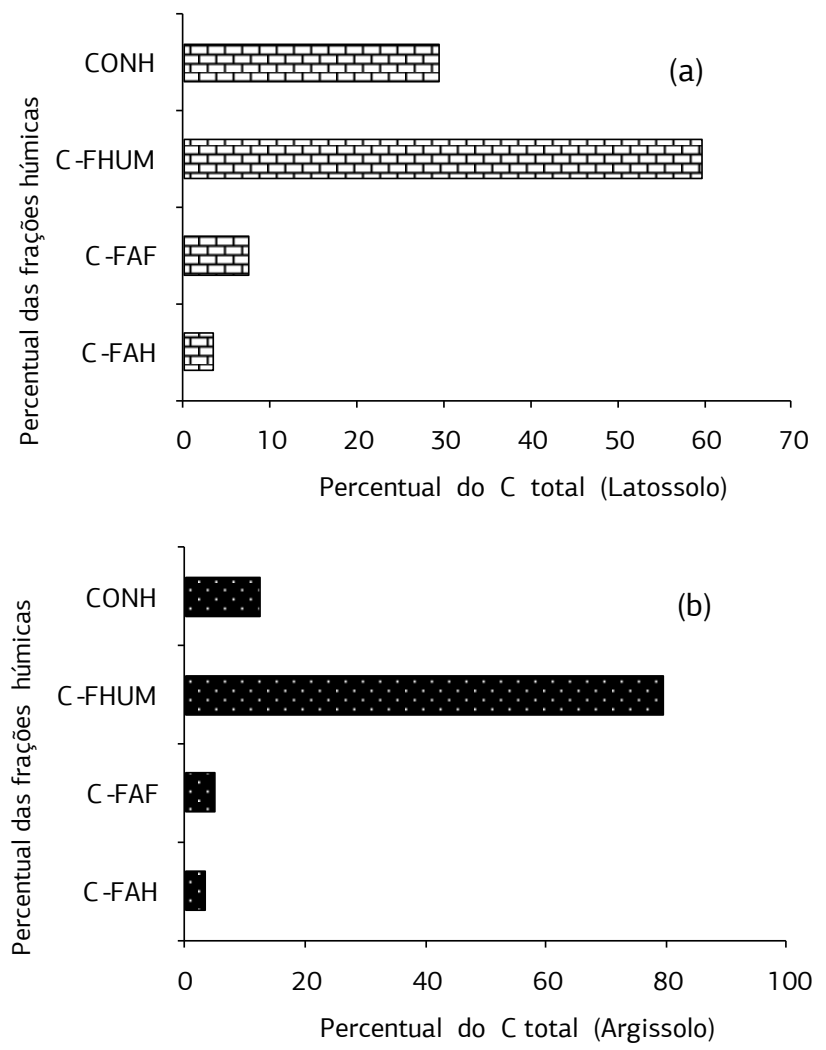

A menor correlação entre o C-FAF, C orgânico total e a redução da relação C-FAH/C-FAF do horizonte A para o $B$ refletem a característica de maior solubilidade e mobilidade da FAF através do solo, distribuindo-se por todos os horizontes e representando o principal fluxo de carbono no sistema. Valores da relação C-FAH/CFAF menores que 1 (um) indicam a evolução limitada da matéria orgânica adicionada, devido ao manejo ou por processos pedogenéticos ou ainda por aporte recente de matéria orgânica, favorecendo a formação da FAF em relação a FAH. Efeito similar foi observado por Bonifácio et al. (2006), estudando a gênese de Espodossolos e Organossolos e Fontana et al. (2008), estudando horizontes diagnósticos de diferentes classes de solo no Brasil.

A razão C-FAH/C-FAF foi usada por Kononova (1982) como um indicador da qualidade do húmus, pois expressa o grau de evoluçáo do processo de humificação da matéria orgânica. Em solos tropicais, normalmente, essa razão é inferior a 1 devido à menor intensidade do processo de humificação, i.e., condensação e síntese, atribuídas à intensa mineralização dos resíduos, restriçóes edáficas e ao baixo conteúdo de bases trocáveis à atividade biológica nos solos mais intemperizados (CANellas et al., 2002). As relaçóes maiores que 1,0 são explicadas por condiçóes de solo e clima, em que os processos de polimerização e
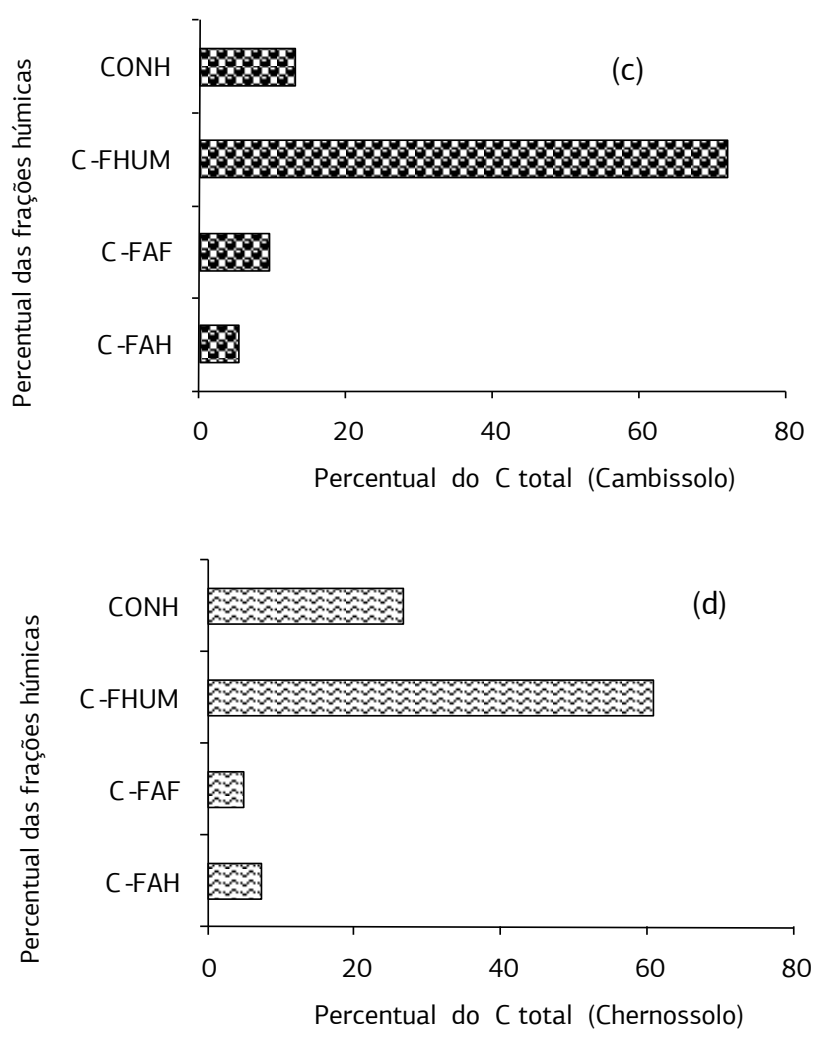

CONH = Carbono orgânico não humificado; C-FHUM = Carbono da fraçăo humina; C-FAF = Carbono da fração ácido fúlvico; C-FAH = Carbono da fração ácido húmico.

Figura 1. Distribuição percentual do teor de C nas fraçôes da matéria orgânica em relação ao C total. (a) Latossolo Amarelo; (b) Cambissolo Háplico; (c) Argissolo Amarelo e (d) Chernossolo Argilúvico. 
Tabela 2. Valores absolutos dos teores de carbono nas frações ácido húmico (FHA), ácido fúlvico (FAF) e humina, carbono total (COT), índices do carbono da FAH:FAF e C-EA:C-HUM e alguns atributos do solo

\begin{tabular}{|c|c|c|c|c|c|c|c|c|c|c|c|c|c|c|c|}
\hline Perfil & Hor & СОT & C-FAH & C-FAF & C-FHUM & SOM & $\begin{array}{l}\text { C-FAH:/ } \\
\text { C-FAF }\end{array}$ & $\begin{array}{l}\text { C-EA: } \\
\text { C-FHUM }\end{array}$ & AG & AF & Sil & Arg & $\mathrm{pH}$ & $\mathrm{Al}^{+3}$ & $\mathbf{H}^{+}$ \\
\hline \multicolumn{9}{|c|}{ C g kg solo-1 } & \multicolumn{4}{|c|}{ g kg solo-1 } & \multicolumn{3}{|c|}{$\mathrm{cmol}_{\mathrm{c}} \mathrm{dm}^{-3}$} \\
\hline Latossolo & A & 34,0 & 1,17 & 2,55 & 20,3 & 70 & 0,46 & 0,18 & 270 & 110 & 80 & 540 & 4,5 & 1,9 & 12,3 \\
\hline Amarelo 1 & Bw2 & 9,7 & 0,29 & 0,28 & 6,6 & 74 & 1,04 & 0,09 & 160 & 80 & 70 & 690 & 4,8 & 0,4 & 4,8 \\
\hline Latossolo & Ap & 49,0 & 0,87 & 1,69 & 35,5 & 78 & 0,51 & 0,07 & 190 & 90 & 250 & 470 & 5 & 0,5 & 13,4 \\
\hline Amarelo 2 & Bw2 & 4,0 & 0,15 & 0,42 & 1,8 & 59 & 0,36 & 0,32 & 150 & 100 & 250 & 500 & 5,2 & 0,4 & 3 \\
\hline Latossolo & Ap & 16,0 & 1,17 & 1,20 & 11,4 & 85 & 0,98 & 0,21 & 130 & 80 & 140 & 650 & 5,1 & 0,7 & 5,1 \\
\hline Amarelo 3 & Bw2 & 7,2 & 0,58 & 0,88 & 5,3 & 94 & 0,66 & 0,27 & 110 & 100 & 90 & 700 & 5,3 & 0 & 3,5 \\
\hline Latossolo & $\mathrm{Ap}$ & 23,0 & 1,03 & 1,54 & 12,1 & 63 & 0,67 & 0,21 & 140 & 270 & 140 & 450 & 4,7 & 2,3 & 8,3 \\
\hline Amarelo 4 & Bw2 & 3,2 & 0,41 & 0,16 & 1,5 & 65 & 2,56 & 0,38 & 130 & 200 & 100 & 570 & 5,1 & 0,1 & 1,9 \\
\hline Cambissolo & $\mathrm{A} 1$ & 37,0 & 2,03 & 3,51 & 26,6 & 87 & 0,58 & 0,21 & 170 & 160 & 260 & 410 & 5 & 2,5 & 14,5 \\
\hline Háplico 5 & $\mathrm{Bi}$ & 4,1 & 0,0 & 0,15 & 2,8 & 72 & 0,00 & 0,05 & 150 & 110 & 260 & 480 & 5,1 & 3,2 & 2,7 \\
\hline Argissolo & Ap & 19,0 & 0,62 & 0,92 & 15,1 & 87 & 0,67 & 0,10 & 50 & 30 & 270 & 650 & 5,2 & 2,3 & 5,4 \\
\hline Amarelo 6 & Bt2 & 6,2 & 0,15 & 0,26 & 3,8 & 67 & 0,58 & 0,11 & 40 & 20 & 190 & 750 & 5,6 & 0,8 & 3,8 \\
\hline Latossolo & Ap & 34,0 & 1,89 & 2,35 & 15,8 & 59 & 0,80 & 0,27 & 10 & 10 & 170 & 810 & 4,7 & 2,8 & 13,8 \\
\hline Bruno 7 & Bw2 & 3,6 & 0,44 & 0,15 & 4,7 & 146 & 2,93 & 0,13 & 20 & 10 & 140 & 830 & 5,2 & 0 & 4,2 \\
\hline Latossolo & Ap & 25,0 & 0,58 & 3,45 & 14,4 & 74 & 0,17 & 0,28 & 10 & 20 & 210 & 760 & 4,5 & 3,5 & 14,5 \\
\hline Bruno 8 & Bw2 & 3,6 & 0,29 & 0,43 & 2,6 & 92 & 0,67 & 0,28 & 20 & 20 & 180 & 780 & 5 & 0,3 & 5,1 \\
\hline Latossolo & Ap & 24,0 & 1,21 & 0,68 & 10,9 & 54 & 1,78 & 0,17 & 10 & 30 & 130 & 830 & 5,9 & 0 & 7,4 \\
\hline Vermelho 9 & Bw2 & 4,2 & 0,45 & 0,13 & 2,5 & 74 & 3,46 & 0,23 & 10 & 20 & 150 & 820 & 5,4 & 0 & 4,7 \\
\hline Chernossolo & $A p$ & 20,0 & 1,47 & 0,98 & 12,2 & 73 & 1,50 & 0,20 & 170 & 190 & 360 & 280 & 7,3 & 0 & 0 \\
\hline Argilúvico 10 & Bt2 & 7,0 & 0,44 & 0,57 & 5,1 & 87 & 0,77 & 0,20 & 110 & 180 & 260 & 450 & 6,4 & 0 & 2,8 \\
\hline Argissolo & $A$ & 42,0 & 1,02 & 4,15 & 22,1 & 65 & 0,25 & 0,23 & 30 & 10 & 200 & 760 & 4,7 & 5,7 & 11,7 \\
\hline Amarelo 11 & $\mathrm{Bt}$ & 6,4 & 0,15 & 0,86 & 4,5 & 86 & 0,17 & 0,23 & 50 & 10 & 170 & 770 & 5,2 & 2,7 & 4,3 \\
\hline Latossolo & Ap & 30,0 & 1,46 & 2,49 & 14,3 & 61 & 0,59 & 0,28 & 10 & 10 & 210 & 770 & 4,2 & 2,9 & 11,6 \\
\hline Bruno12 & Bw2 & 5,8 & 0,73 & 1,03 & 3,6 & 92 & 0,71 & 0,49 & 10 & 10 & 120 & 860 & 4,9 & 0,2 & 4,6 \\
\hline Latossolo & Ap & 15,0 & 0,42 & 1,14 & 6,9 & 57 & 0,37 & 0,23 & 140 & 80 & 240 & 540 & 5 & 1,2 & 5,2 \\
\hline Vermelho 13 & Bw2 & 3,9 & 0,14 & 0,71 & 2,9 & 96 & 0,20 & 0,29 & 100 & 70 & 240 & 590 & 5,5 & 0 & 2,2 \\
\hline Latossolo & Ap & 7,3 & 0,99 & 1,69 & 2,5 & 71 & 0,59 & 1,07 & 530 & 240 & 60 & 170 & 4,9 & 0,9 & 2,6 \\
\hline Vermelho 14 & Bw2 & 1,0 & 0,28 & 0,42 & 1,6 & 233 & 0,67 & 0,43 & 450 & 250 & 60 & 240 & 5 & 0,4 & 0,8 \\
\hline Argissolo & Ap & 19,0 & 3,35 & 1,04 & 9,7 & 74 & 3,22 & 0,45 & 180 & 340 & 160 & 320 & 6,5 & 0 & 2,7 \\
\hline Vermelho 15 & Bt2 & 3,1 & 0,29 & 0,88 & 2,3 & 111 & 0,33 & 0,52 & 100 & 200 & 110 & 590 & 5,6 & 0 & 2,1 \\
\hline Argissolo & $\mathrm{A} 1$ & 5,9 & 1,46 & 0,75 & 2,5 & 80 & 1,95 & 0,87 & 110 & 230 & 600 & 60 & 4,2 & 0,4 & 2,1 \\
\hline Vermelho 16 & Bt2 & 3,9 & 0,29 & 0,30 & 1,4 & 51 & 0,97 & 0,42 & 60 & 440 & 160 & 340 & 4,7 & 2 & 1,8 \\
\hline Argissolo & A & 8,6 & 1,69 & 1,14 & 3,6 & 75 & 1,48 & 0,78 & 480 & 320 & 140 & 60 & 4,3 & 0,6 & 2,7 \\
\hline Vermelho 17 & Bt2 & 1,9 & 0,15 & 0,30 & 1,1 & 79 & 0,50 & 0,43 & 390 & 260 & 130 & 220 & 4,7 & 0,5 & 1,4 \\
\hline Chernossolo & $\mathrm{A} 1$ & 12,0 & 1,31 & 0,85 & 5,8 & 67 & 1,54 & 0,37 & 370 & 150 & 230 & 250 & 7,5 & 0 & 0 \\
\hline Argilúvico 18 & $\mathrm{Bt}$ & 3,6 & 0,44 & 0,57 & 2,5 & 97 & 0,77 & 0,41 & 230 & 160 & 290 & 320 & 7 & 0 & 1,1 \\
\hline
\end{tabular}

COT = Carbono orgânico total; C-FAH = Carbono da fração ácido húmico; C-FAF = Carbono da fração ácido Fúlvico C-HUM = Carbono da fração humina; SOM = Soma das fraçóes húmicas; C-FAH:C-FAF = Carbono da fraçáo ácido húmico pelo Carbono da fração ácido Fúlvico; C-EA:C-HUM = Carbono do extrato alcalino pelo carbono da fraçáo humina; $\mathrm{AG}=$ Areia grossa; $\mathrm{AF}=$ Areia fina; $\mathrm{SIL}=$ Silte; $\mathrm{ARG}=$ Argila; $\mathrm{Al}^{3+}=$ Alumínio; $\mathrm{H}^{+}=$Hidrogênio.

condensação são favoráveis, como em Organossolos, onde VALLADARES et al. (2007) verificou valores superiores a 14. Já os valores menores que 1,0 indicam perda seletiva do C-FAF e ou desfavorecimento da síntese e acumulação da fraçáo mais estável (C-FAH) (FonTANA et al., 2005; 2008; BonifÁcio et al., 2006)

Os solos de textura argilosa a muito argilosa (perfis 2, 6, 11 e 13) possuem teor mais elevado de carbono, especialmente na forma da FAF (Tabela 2). Para MendonÇA e Rowell (1996) os ácidos fúlvicos possuem maior capacidade de formar complexos argilo-húmicos, que torna esses ácidos mais estáveis que os ácidos húmicos e, por consequência, mais importantes na formação dos agregados em solos com textura argilosa. Esses mesmos autores trabalharam com Latossolos Vermelho-Amarelo e encontraram maiores conteúdos de $\mathrm{C}$ nos solos de textura argilosa do que nos de textura arenosa. Desta forma, solos mais argilosos apresentam uma maior capacidade de retenção de ácidos fúlvicos (Assis et al., 2006).

Dentre as fraçóes a de melhor correlação com o conteúdo de Corg foi a FHUM, com coeficiente de $r=0,89^{* *}$ para o horizonte A (Figura 2) e $r=0,91^{* *}$ no horizonte B (Figura 3).

$\mathrm{Na}$ tabela 3, observa-se correlação positiva (5\% de significância), entre a fração areia grossa (AG) e C-FAF, C-FAH, C-FHUM e a relação C-EA/C-FHUM, 


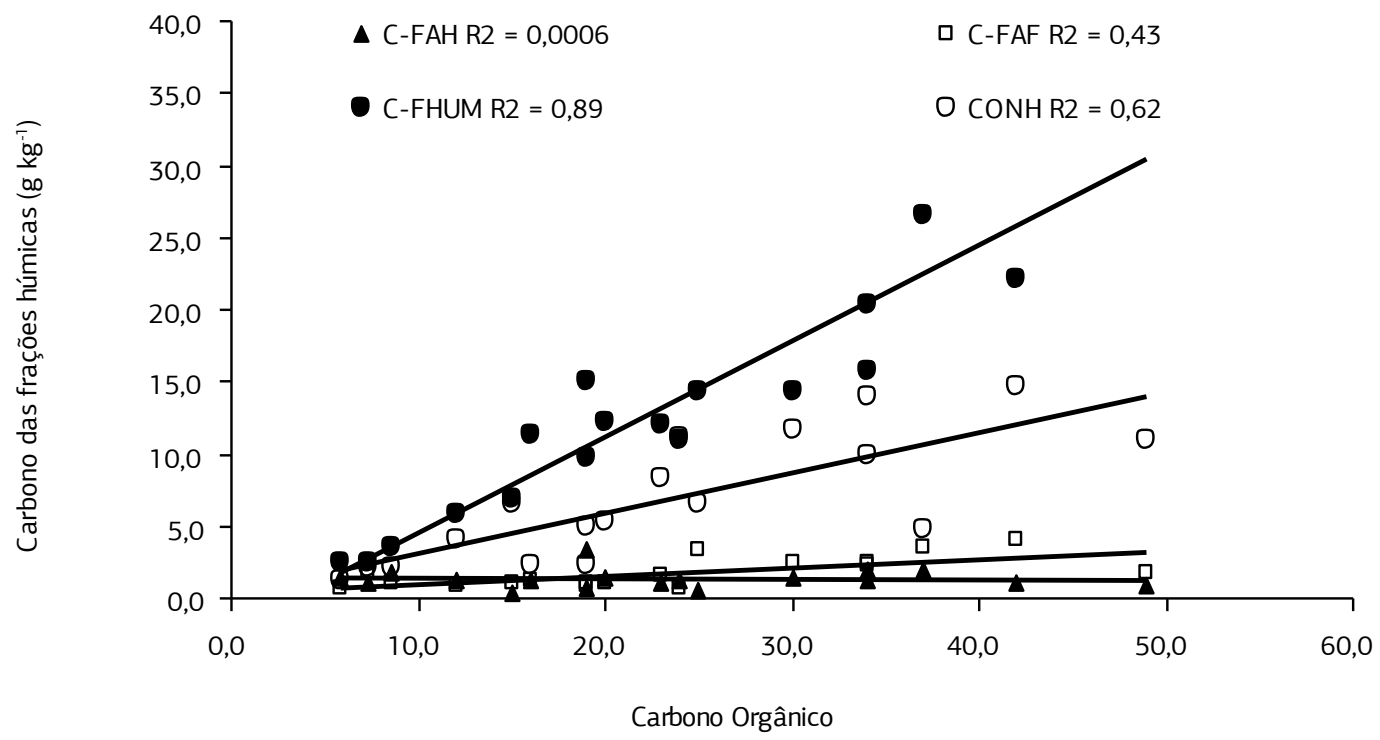

CONH = Carbono orgânico não humificado; C-FHUM = Carbono da fração humina; C-FAF = Carbono da fraçâo ácido fúlvico; C-FAH = Carbono da fração ácido húmico

Figura 2. Relação entre as fraçôes húmicas e teor de C orgânico $\left(\mathrm{g} \mathrm{kg}^{-1}\right)$ do horizonte A dos perfis de solos.

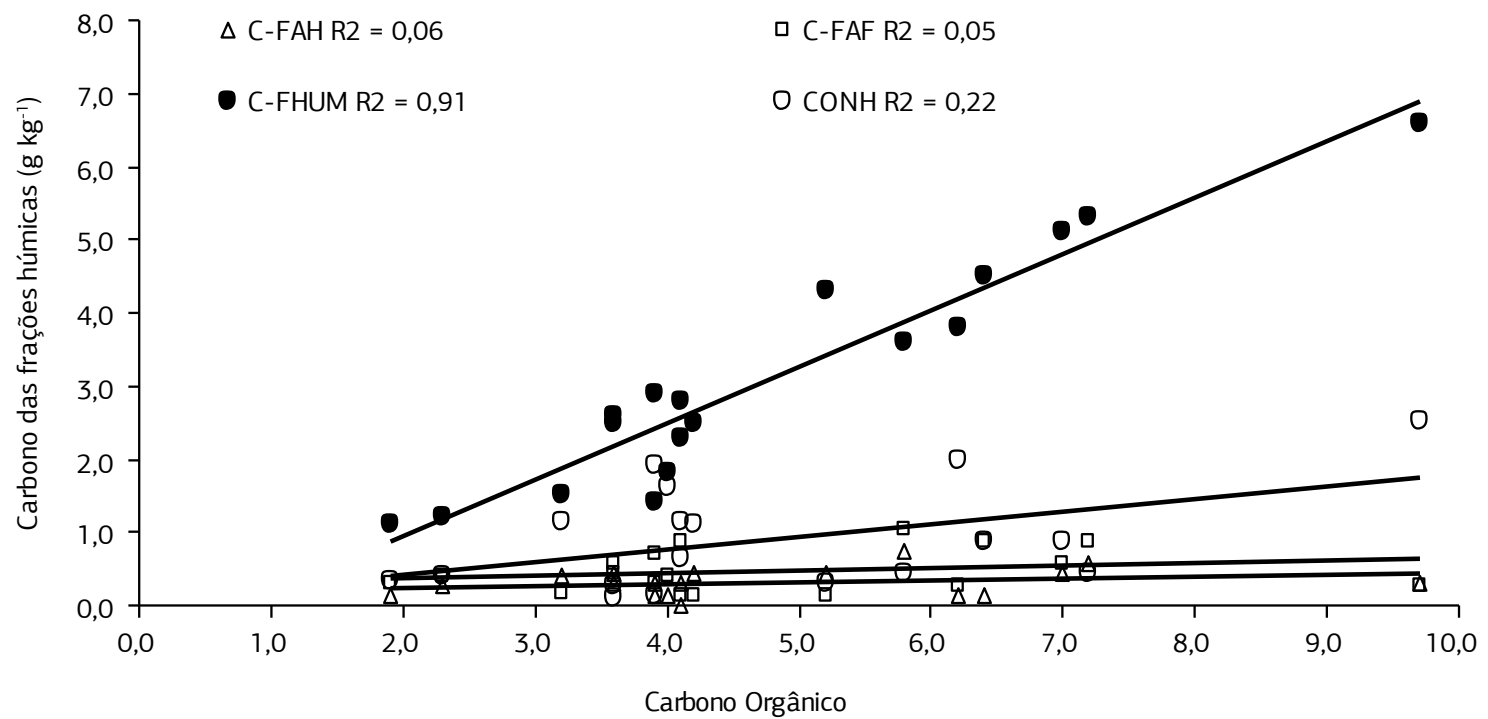

CONH = Carbono orgânico não humificado; C-FHUM = Carbono da fração humina; C-FAF = Carbono da fraçāo ácido fúlvico; C-FAH = Carbono da fraçāo ácido húmico.

Figura 3. Relação entre as fraçóes húmicas e teor de $\mathrm{C}$ orgânico $\left(\mathrm{g} \mathrm{kg}^{-1}\right)$ do horizonte $\mathrm{B}$ dos perfis de solos.

Tabela 3. Correlação entre propriedades do horizonte A e as substâncias húmicas

\begin{tabular}{|c|c|c|c|c|c|c|}
\hline Propriedades & Corg & C-FAF & C-FAH & C-HUM & C-FAH/ C-FAF & C-EA/ C-HUM \\
\hline AG & ns & $0,75^{* *}$ & $0,60^{*}$ & $0,57^{*}$ & ns & $0,73^{* *}$ \\
\hline $\mathrm{AF}$ & ns & $0,55^{*}$ & $0,55^{*}$ & ns & ns & ns \\
\hline SIL & ns & ns & $0,55^{*}$ & ns & ns & $-0,55^{*}$ \\
\hline ARG & ns & $-0,69^{*}$ & ns & ns & ns & $-0,62^{*}$ \\
\hline $\mathrm{pH}$ & ns & ns & ns & ns & $0,78^{* *}$ & ns \\
\hline $\mathrm{Ca}$ & ns & ns & ns & ns & $0,70^{*}$ & ns \\
\hline Al & ns & ns & ns & ns & $-0,57^{*}$ & ns \\
\hline $\mathrm{H}$ & $0,58^{*}$ & $-0,64^{*}$ & ns & ns & ns & ns \\
\hline
\end{tabular}

Corg = Carbono orgânico total; C-FAH = Carbono da fraçăo ácido húmico; C-FAF = Carbono da fraçăo ácido Fúlvico C-HUM = Carbono da fração humina; C-FAH:C-FAF = Carbono da fraçăo ácido húmico pelo Carbono da fraçāo ácido Fúlvico; C-EA:C-HUM = Carbono do extrato alcalino pelo carbono da fração humina; H+ = Hidrogênio; AG $=$ Areia grossa; $\mathrm{ARG}=$ Argila; $\mathrm{SIL}=$ Silte. $\mathrm{Ns}=$ náo significativo; ${ }^{* * *}=$ significativo a $5 \%$; e a $1 \%$ respectivamente. 
mostrando que a textura mais arenosa do horizonte A favoreceu a formação destas fraçóes. Este comportamento não foi verificado para o horizonte B (Tabela 4). Resultados semelhantes foram observados por CunHA et al. (2001).

Quanto às propriedades químicas, tanto para o horizonte A quanto para o horizonte B (Tabelas 3 e 4), foram verificadas correlaçóes positivas para o horizonte $A$ $\left(\mathrm{r}=0,58^{*}\right)$, e para o horizonte $\mathrm{B}\left(\mathrm{r}=0,83^{* *}\right)$ entre o hidrogênio e o conteúdo de carbono orgânico. EbeLING et al. (2008) também observou altas correlaçôes, evidenciando que quanto maior o conteúdo de carbono maior tenderá ser a acidez do solo, interferindo diretamente na formação das $\mathrm{SH}$.

O C-FAH proporcionou correlação negativa a 5\% $\left(\mathrm{r}=-0,64^{*}\right)$ com o hidrogênio para o horizonte $\mathrm{A}$, demonstrando que a maior acidez dos solos influencia diretamente na formação dessa fração orgânica, comportamento que não foi verificado no horizonte $\mathrm{B}$. Para o horizonte $\mathrm{A}$, observa-se que na relaçáo C-FAH/C-FAF houve correlação positiva e significativa a $1 \% \mathrm{com}$ o pH e a $5 \% \mathrm{com}$ os teores $\mathrm{Ca}^{2+} \mathrm{e}^{3}{ }^{3+}$, demonstrando que o aumento desta relação é dependente das variaçóes de $\mathrm{pH}$ e dos teores de Ca no solo.

Os teores de carbono nas três fraçóes húmicas promovem correlação significativa com os valores de $\mathrm{H}^{+}$. Os coeficientes de correlação (Tabela 5) foram maiores para os teores de C-FAF $\left(0,82^{* *}\right)$ e humina $\left(0,82^{* *}\right)$ e menores para os teores de C-FAH $\left(0,30^{* *}\right)$, demonstrando que a maior acidez do solo influencia diretamente na formação das fraçôes orgânicas. O aumento da concentração dos ácidos fúlvicos e húmicos é acompanhado pelo aumento da concentraçáo de $\mathrm{H}^{+}$(Tabela 2), principalmente nos solos com textura mais argilosa. O relevo também influência na formação de humina, o maior conteúdo de argila nas posiçóes mais elevadas do relevo estabiliza e protege grande parte do C orgânico da mineralização (Volkoff et al., 1984; CANellas et al., 2000).

Os valores percentuais da FAF e FAH correlacionaram-se com os teores de argila e AG (Tabela 5), demonstrando que essas fraçôes granulométricas estáo relacionadas com grau de transformação da MOS. Uma pequena parte dos solos estudados propiciou menores porcentagens de Corg na forma da FAF do que na forma da FAH; este é um dos fatores que podem colaborar para menor lixiviação ou translocação de elementos no perfil do solo (GreEnland, 1965; Canellas et al., 2000). Os valores percentuais de ácidos húmicos e humina possuem correlação com os teores de $\mathrm{Al}^{3+}$, comportamento similar ao observado para o $\mathrm{H}^{+}$. A formação de complexos solúveis com a matéria orgânica pode favorecer reaçóes de hidrólise, aumentar a mobilização e o transporte de metais. A formação de complexos insolúveis provoca o aumento relativo em profundidade de $\mathrm{Al}$ e $\mathrm{Fe}$ (Canellas et al., 2000).
Todos os perfis têm maiores teores do C-FHUM em todos os horizontes superficiais e subsuperficiais, com variação de seus valores de $45 \%$ a $79 \%$, porém, dentre as frações humificadas houve uma variação na concentração dos C-FAFL, C-FAF, C-FAH, e C-FHUM em alguns perfis. A mineralogia mais oxídica pode ter atuado como fonte de $\mathrm{Al} \mathrm{e} \mathrm{Fe}$, complexando e retendo o húmus na forma de humina. Esse processo confere certa estabilidade na MOS (Pirakornphanich et al., 1988; Mendonça e Rowell, 1996; Assis et al., 2006).

Nos perfis 1, 8, 11, 12 e 14 a FHUM predominou sobre as outras, porém a FAF teve maior participação, em relação às outras fraçôes para o horizonte $\mathrm{A}$, provavelmente explicado pela altitude e o clima Cwa e Cfb em que se localizam os perfis que favorecem a formação da FAF.

Os perfis 2, 3, 4, 5, 6, 7 e 13 tiveram a maior concentraçáo da FHUM seguida pela FAFL. Nestes perfis, de altitude elevada, o clima Cwa, Cfb, Cwb favoreceu a formação da FAFL. Para os perfis 9, 10, 15, 16, 17 e 18, novamente a FHUM estava em maior concentração, mostrando que é encontrada na maioria dos solos em maior quantidade. A predominância da fração humina deve-se às suas características de alta massa molecular e à forte interação com a fração mineral do solo (Stevenson, 1994), o que lhe confere alta resistência à degradação microbiana.

Estes perfis, localizados em regióes de clima Cfa, possuem maior concentração da FAH logo após a FHUM. Tal comportamento, possivelmente, pode ser atribuído ao baixo teor de argila, às boas condiçóes de drenagem,

Tabela 4. Correlação entre propriedades do horizonte B e as substâncias húmicas

$\begin{array}{lcccc}\text { Propriedades } & \text { Corg } & \text { C-FAF } & \text { C-FAH } & \text { C-EA:C-HUM } \\ \text { AG } & \text { ns } & 0,65^{*} & 0,64^{*} & \text { ns } \\ \text { SIL } & \text { ns } & \text { Ns } & -0,68^{*} & \text { ns } \\ \text { ARG } & \text { ns } & -0,56^{*} & \text { ns } & \text { ns } \\ \text { H } & 0,83^{* *} & \text { Ns } & -0,67^{*} & \text { ns }\end{array}$

Corg = Carbono orgânico total; C-FAH = Carbono fraçâo ácido húmico; $\mathrm{C}-\mathrm{FAF}=$ Carbono fração ácido Fúlvico C-HUM = Carbono fraçăo humina; C-EA:C-HUM = Carbono do extrato alcalino pelo carbono da fração humina; $\mathrm{H}+=$ Hidrogênio; $\mathrm{AG}$ $=$ Areia grossa; $\mathrm{ARG}=$ Argila; $\mathrm{SIL}=\mathrm{Silte} . \mathrm{N} s=$ nāo significativo. ${ }^{*, * *}=$ significativo a $5 \%$ e a $1 \%$ respectivamente.

Tabela 5. Coeficiente de correlação de Pearson envolvendo algumas propriedades dos perfis estudados $(\mathrm{n}=34)$

$\begin{array}{lcccc}\text { Frações/Propriedades } & \mathbf{H}^{+} & \text {AG } & \text { ARG } & \text { Al } \\ \text { C-FAH } & 0,30^{*} & - & - & - \\ \text { C-FAF } & 0,82^{* *} & - & - & - \\ \text { C-HUM } & 0,82^{* *} & - & - & - \\ \text { C-FAHP } & - & 0,46^{* *} & -0,54^{* *} & - \\ \text { C-FAFP } & - & -0,44^{*} & -0,30^{*} & -0,46^{* *} \\ \text { C-HUMP } & - & - & - & 0,46^{* *}\end{array}$

$\mathrm{H}^{+}=$Hidrogênio; $\mathrm{AG}=$ Areia grossa; $\mathrm{ARG}=$ Argila total; $\mathrm{Al}=$ Alumínio; $\mathrm{C}-\mathrm{FAH}=$ Carbono da fração ácido húmico; C-FAF = Carbono da fraçáo ácido fúlvico C-HUM = Carbono da fração humina; C-FAHP = Carbono da fraçấo ácido húmico em percentual; C-FAFP = Carbono da fração ácido fúlvico em percentual; $\mathrm{C}-\mathrm{HUMP}=$ Carbono da fraçấo humina em percentual. 
à alta atividade biológica, e às características de elevada solubilidade e mobilidade dos ácidos fúlvicos que podem favorecer a percolação pelo perfil do solo.

A matéria orgânica humificada nestes perfis esteve em torno de $79,6 \%$. A análise da distribuição das frações da $\mathrm{MO}$ e as características e propriedades dos solos permitem indicar que a principal via de formação das SHs nos perfis estudados é a da insolubilização, como a humificaçáo de compostos fenólicos solúveis, a partir da sua oxidação a quinonas e polimerizaçáo, formando unidades orgânicas precursoras das SHs. Com a policondensação de núcleos aromáticos, são formadas as FAF que, ao se condensarem, originam as FAH. A formação da FHUM, estádio final do processo de humificação é caracterizada pela estabilização química e física dos compostos orgânicos com a fraçáo mineral do solo, e a via de condensação abiótica de compostos fenólicos náo é a preferencial da gênese de SHs (Canellas et al., 2000; Anjos et al., 2008).

\section{CONCLUSÕES}

1. A fração humina predomina em todos os perfis estudados, indicando a resistência desta fração à decomposição microbiana e a elevada interação desta fração com a porção mineral do solo.

2. O clima Cwa e Cfb, pela classificação de Köppen, parece favorecer a formação da fração ácido fúlvico em detrimento da fração ácido húmico em ambientes de altitude. Já o teor de carbono das fraçóes ácido húmico e ácido fúlvico, expressos em percentual, apresenta correlaçáo com os teores de areia grossa, de argila e de alumínio.

3. O comportamento das fraçóes da matéria orgânica do solo é alterado em função do ambiente de formação, material de origem, clima e composição granulométrica interferindo diretamente em sua gênese.

\section{AGRADECIMENTO}

Os autores agradecem a CPGA-CS, CAPES e ao CNPq pelo financiamento do projeto.

\section{REFERÊNCIAS}

ASSIS, C.P.; JUCKSCH, I.; MENDONCA, E.S.; NEVES, J.C.L. Carbono e nitrogênio em agregados de Latossolo submetido a diferentes sistemas de uso e manejo. Pesquisa Agropecuária Brasileira, v.41, p.1541-1550, 2006.

ANJOS, L.H.; PEREIRA, M.G.; FONTANA, A. Matéria orgânica e pedogênese. In: SANTOS, G.A.; SILVA, L.S.; CANELLAS, L.P.; CAMARGO, F.A.O. (Eds.) Fundamentos da matéria orgânica do solo: ecossistemas tropicais e subtropicais. 2. ed. Porto Alegre: Metrópole, 2008. p.65-86.

BAYER, B.; MIELNICZUK, J.; MARTIN-NETO, L.; ERNANI, P.R. Stocks and humification degree of organic matter fractions as affected by no-tillage on a subtropical soil. Plant and Soil, v.238, p.133-140, 2002.

BENITES, V.M.; CAIAFA, A.N.; MENDONÇA, E.S.; SCHAEFFER, C.E.G.R.; KER, J.C. Solos e vegetação nos Complexos Rupestres de Altitude da Mantiqueira e do Espinhaço. Floresta e Ambiente, v.10, p.76-85, 2003.

BENITES, V.M.; SCHAEFER, C.E.G.R.; MENDONÇA, E.S.; MARTIN NETO, L. Caracterização da matéria orgânica e micromorfologia de solos sob Campos de Altitude no Parque Estadual da Serra do Brigadeiro. Revista Brasileira de Ciência do Solo, v.25, p.661-674, 2001.

BENITES, V.M. Caracterização química e espectroscópica da matéria orgânica e suas relaçóes com a gênese de solos da serra de Brigadeiro, zona da mata mineira. 1998, 125f. Dissertação (Mestrado em Agronomia) Universidade Federal de Viçosa, UFV.

BONIFACIO, E.; SANTONI, S.; CELI, L.; ZANINI, E. Spodosol - Histosol evolution in the Krkonos`e National Park (CZ). Geoderma, v.131, p.237-250, 2006.

CANELLAS, L.P., VELLOSO, A.C.X., RUMJANEK, V.M., GURIDI, F., OLIVARES, F.L., SANTOS, G.A., BRAZ-FILHO, R. Distribution of the humified fractions and characteristics of the humic acids of an Ultisol under cultivation of Eucalyptus and sugar cane. Terra, v.20, p.371-381. 2002.

CANELLAS, L.P.; BERNER, P.G.; SILVA, S.G.; SILVA, M.B.; SANTOS, G.A. frações da matéria orgânica em seis solos de uma toposseqüência no estado do Rio de Janeiro. Pesquisa Agropecuária Brasileira, v.35, p.133-143, 2000.

CUNHA, T.J.F.; MENEGUELLI, N.A.; CONCEIÇÃO, M.; MACHADO, P.L.O.A.; FREIXO, A.A. Avaliaçấo de extratores de substâncias húmicas de um Latossolo Vermelho Distroférrico Rio de Janeiro. Embrapa Solos, 2000. 15p. (Embrapa Solos. Boletim de Pesquisa, n.7)

CUNHA, T.J.F.; MACEDO, J.R.; RIBEIRO, R.P.; PALMIERI, F.; FREITAS, P.L.; AGUIAR, A.C. Impacto do manejo convencional sobre propriedades físicas e substâncias húmicas de solos sob cerrado. Ciência Rural, v.1, p.27-36, 2001.

EBELING, A.G.; ANJOS, L.H.C.; PEREZ, D.V.; PEREIRA, M.G.; VALLADARES, G.S. Relaçấo entre acidez e outros atributos químicos em solos com teores elevados de matéria orgânica. Bragantia, v.67, p.261-266, 2008.

EMBRAPA. Centro Nacional de Pesquisa de Solos. Serviço Nacional de Levantamento e Conservaçấo do Solo. Manual de métodos de análise de solo. Rio de Janeiro: Embrapa Solos, 1997. 212p.

EMBRAPA. Centro Nacional de Pesquisa de Solos. Sistema brasileiro de classificação de solos. 2.ed. rev. atual. Brasília: Embrapa Produção de Informação; Rio de Janeiro: Embrapa Solos, 2006. 306p. 
FERREIRA, J.A.; SIMÓES, M.L.; MILORE, D.M.B.P.; MARTINNETO, L.; HAYES, M.H.B. Caracterização Espectroscópica da Matéria Orgânica do Solo. Embrapa Sáo Carlos, 2004. (Circular Técnica, 24)

FONTANA, A.; ANJOS, L.H.C.; SALLÉS, J.M.; PEREIRA, M.G.; ROSSIELLO, O.R.P. Carbono orgânico e fracionamento químico da matéria orgânica em solos da Sierra de Ánimas Uruguai. Floresta e Ambiente, v.12, p.36-43, 2005.

FONTANA, A.; NASCIMENTO, G.B.; ANJOS, L.H.C.; PEREIRA, M.G.; EBELING, A. G. Matéria orgânica em solos de Tabuleiros na regiáo norte fluminense (RJ). UFRRJ, Floresta e Ambiente, v.8, p.114-119. 2001.

FONTANA, A.; PEREIRA, M.G.; ANJOS, L.H.C.; BENITES, V.M. Distribution of organic carbon in the humic fractions of diagnostic horizons from Brazilian soils. Communications in Soil Science and Plant Analysis, v.39, p.951-971, 2008.

GREENLAND, D.J. Interaction between clays and organic compounds in soils. 2. Adsorption of soil organic compounds and its effect on soil properties. Soil and Fertilitizers, v.28, p.232-251, 1965.

JOHNSON, J.M.F.; FRANZLUEBBERS, A.J.; WEYERS, S.L.; REICOSKI, D.C. Agricultural opportunities to mitigate greenhouse gas emissions: a Review. Environmental Pollution, v.150, p.107-124, 2007.

KONONOVA, M.M. Materia orgánica del suelo: su naturaleza, propiedades y métodos de investigación. Barcelona: Oikos-tau, 1982. 364p.

KONONOVA, M.M. Soil organic matter: its nature, its role in soil formation and in soil fertility. 2ed. New York: Pergamon Press, 1966. 544p.

LAL, R. Soil carbon sequestration impacts on global climate change and food security. Science, v.304, p.1623-1627, $2004 a$.
LAL, R. Soil carbon sequestration to mitigate climate change: a review. Geoderma, v.123, p.1-22, 2004 b.

MENDONÇA, E.S.; ROWELL, D.L. Mineral and organic fractions of two oxisols and their influence on effective cationexchange capacity. Soil Science Society of America Journal, v.60, p.188-192, 1996.

NELSON, D.W. \& SOMMERS, L.E. Total carbon, organic carbon and organic matter. American Society of Agronomy, v.9, p.539-577, 1982 .

ORLOV, D.S. Humic substances of soils and general theory of humification. Moscow: University Press, 323p. 1992.

PIRAKORNPHANICH, P.; WADA, S.I.; WADA, K. Metalhumus complexes in a horizon of Thai and Kovan red and yellow soils. Journal of Soil Science, v.39, p.529-537, 1988.

ROSCOE, R. Rediscutindo o papel dos ecossistemas terrestres no seqüestro de carbono. Caderno de Ciência \& Tecnologia, v.20, p.209-223, 2003.

STEVENSON, F.J. Humus Chemistry. Genesis, Composition, Reaction. 2.ed. New York: John Wiley, 1994. 443p.

VALLADARES, G.S.; PEREIRA, M.G.; ANJOS, L.H.C.; BENITES, V.M.; EBELING, A.G.; MOUTA, R.O. Humic substance fractions and attributes of histosols and related highorganic-matter soils from brazil. Communications in Soil Science and Plant Analysis, v. 38, p.763-777, 2007.

VOLKOFF, B.; CERRI, C.C.; MELFI, J.A. Húmus e mineralogia dos horizontes superficiais de três solos de campo de altitude dos Estados de Minas Gerais, Paraná e Santa Catarina. Revista Brasileira de Ciência do Solo, v.8, p.277-283, 1984.

VOLKOFF, B.; FLEXOR, J.M.; SANTA-ISABEL, L.M.; SANTAISABEL, M. Natureza do húmus nos Latossolos distróficos da Bahia. Revista Brasileira de Ciência do Solo, v.2, p.59-63, 1978. 